\title{
La Revista Mexicana de Anestesiología con paso firme y adecuado a la modernidad
}

\author{
Revista Mexicana de Anestesiología with a firm \\ and appropriate step towards modernity
}

Acad. Dr. Raúl Carrillo-Esper*

Citar como: Carrillo-Esper R. La Revista Mexicana de Anestesiología con paso firme y adecuado a la modernidad. Rev Mex Anestesiol. 2022; 45 (1): 7-8. https://dx.doi.org/10.35366/102895

ت1 n el siglo pasado, específicamente el 20 de noviembre de 1934 se fundó en la Ciudad de $\amalg$ México la Sociedad de Anestesistas de México, por los Doctores Benjamín Bandera, Emilio Varela, Francisco Cid Fierro, Juan White Morquecho y Federico Vollbrechthausen. A esta agrupación científica primigenia, antecedente de la Sociedad Mexicana de Anestesiología que dio paso al ahora Colegio Mexicano de Anestesiología (CMA), se fueron incorporando socios, en su momento, al igual que los fundadores, médicos de gran importancia en su época, destacando los Doctores Darío Fernández, José Castro Villagrana, Rosendo Amor y Ulises Valdez, por mencionar a algunos. La actividad académica era el centro de las actividades de este incipiente grupo, sesionando en el consultorio del Dr. White Morquecho que se encontraba ubicado en la Avenida Juárez. Con el entusiasmo y visión vanguardista que caracterizaba a este selecto grupo médico rápidamente la Sociedad de Anestesistas de México estaba bien organizada, sesionaba y extendía diplomas. Acorde a su fundación el Maestro y Académico Dr. Benjamín Bandera cita lo siguiente: [...] «Faltos de datos para asignar la fecha exacta de fundación de esta organización, tomamos en 20 de noviembre de 1934, en que públicamente hicimos acto de presencia como Sociedad, en una reunión importante como lo fue la Convención de Cirujanos y que a partir de ella dejamos constancia oficial de nuestra existencia» ${ }^{(1)}$.

La Revista Mexicana de Anestesiología tiene como antecedente el fascículo al que se denominó Anestesia, cuyo primer número fue publicado en 1936 en forma de fascículo, en la Revista Cirugía, Tomo VII número 7, publicación del Hospital Juárez de México. De esta manera podemos considerar que Anestesia fue la primera publicación dedicada a texto completo a la Anestesiología en América Latina (ya que la Revista Argentina de Anestesiología apareció en 1939) y precursora de la Revista Mexicana de Anestesiología (RMA) ${ }^{(2)}$.

La RMA es el Órgano Oficial de Divulgación Científica del Colegio Mexicano de Anestesiología. A partir de su creación por el Dr. Benjamín Bandera en el año de 1952 se ha publicado de manera ininterrumpida en tiempo y forma gracias al esfuerzo y entusiasmo de Editores, Comités Editoriales, Mesas Directivas e Investigadores, todos comprometidos con la promoción de la investigación clínica y divulgación del conocimiento científico. Los inicios no fueron fáciles, la impresión era en papel y su distribución limitada a unos cuantos anestesiólogos, al paso del tiempo se fue fortaleciendo, mejorando el proceso editorial, el número de trabajos publicados, además de alcanzar un mayor tiraje y distribución.

La RMA ha adecuado y modernizado su contenido, proceso y diseño editorial e imagen acorde a los avances científicos y tecnológicos. Sus páginas son fieles testigos de la evolución de la Anestesiología Mexicana contemporánea, legado que perdurará al paso de los años.

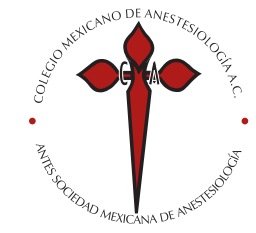

* División de Áreas Críticas. Instituto Nacional de Rehabilitación «Luis Guillermo Ibarra Ibarra».

Correspondencia: Dr. Raúl Carrillo-Esper Instituto Nacional de Rehabilitación Luis Guillermo Ibarra Ibarra. Calz. México-Xochimilco No. 289, Coapa, Arenal Tepepan, Tlalpan, 14389, CDMX. E-mail: raulcarrilloesper@ gmail.com 
Con satisfacción les comparto que la RMA se renueva constantemente y se mantiene a la vanguardia. Su imagen de portada se adecúa a la modernidad y mantiene los colores de nuestra corporación. Ofrece al lector el índice del contenido, lo que invita a la lectura de los trabajos seleccionados para su análisis. Desde el punto de vista editorial se organiza en las secciones de editoriales, investigaciones originales, artículos de revisión, casos clínicos, imágenes en anestesiología, historia de la anestesiología y cartas al editor. Se procura mantener en cada uno de los números el balance entre cada una de las secciones.

En cuanto al proceso editorial, se han logrado avances de importancia. Los trabajos enviados a publicación son sometidos a revisión por pares, lo que asegura la calidad y contenido de cada uno de los artículos publicados. La comunicación entre autores, editores, comité editorial y revisores se realiza por medio electrónico, lo que favorece una comunicación más fluida y rápida. Para modernizar este proceso y hacerlo más ágil se está implementando un sistema informático de revisión que hará más fluida y expedita la comunicación y que reemplazará progresivamente al proceso editorial actual.

Una de las fortalezas de la RMA es contar con un repositorio electrónico de cada uno de los volúmenes y números a partir de la primera publicación, lo que asegura la consulta y el resguardo del trabajo de todos los actores que han contribuido en su edición. La adecuación a la modernidad y el uso de nuevas tecnologías editoriales nos ha permitido que además de su versión impresa, que ya es un clásico de colección en el área de la anestesiología, la RMA se publica por vía electrónica en texto completo en versión PDF y en formato Flipbook. Esta última ofrece al lector la oportunidad de consultar la revista en versión digital como si la tuviera en papel. Una de las grandes ventajas que da la impresión electrónica es que tanto en el formato PDF como en el Flipbook los artículos en su contenido completo aparecen a color, lo que los hace más atractivos y ágiles para los lectores y, de seguro, dan gran satisfacción a los investigadores que ven plasmado su esfuerzo en una publicación de fácil consulta, ágil y de acceso global.

El fomento de la investigación y la difusión del conocimiento son dos importantes objetivos del CMA. La RMA cumple a cabalidad con estos dos objetivos, ya que ofrece una plataforma para los investigadores y al difundirse en sus diferentes versiones ofrece tanto a colegiados como a todos los interesados en la anestesiología y especialidades afines una excelente herramienta para la actualización continua. En este sentido es importante hacer de su conocimiento que la RMA es de acceso libre, lo que está acorde a otro de los principios básicos del colegio, que es el servicio social. Esta apertura y su impresión digital han favorecido que la difusión de la productividad científica mexicana en el área de la anestesiología llegue no sólo a los médicos mexicanos, sino más allá de nuestras fronteras, en el entendido de que el conocimiento debe ser universal y compartido.

La RMA desde su creación avanza con paso firme al futuro, cumple y es parte de la misión y esencia del CMA y del espíritu de los fundadores, al fomentar la investigación y difusión del conocimiento en un marco humanista, de servicio social y acorde a la modernidad.

\section{REFERENCIAS}

1. Bandera B. Historia de la Anestesiología en México: evolución y desarrollo futuro. Rev Mex Anest. 1960;9:83-94.
2. Marrón-Peña M, Moreno-Alatorre C. Antecedentes Históricos del Colegio Mexicano de Anestesiología, antes Sociedad Mexicana de Anestesiología: sus orígenes, evolución y trascendencia (1934-1995). Rev Mex Anest. 2013;36:136-154. 